\title{
O CAMPO E A CIDADE NA REFORMA AGRÁRIA: UMA ANÁLISE DO TRABALHO E DO TERRITÓRIO ${ }^{1}$
}

\section{EL CAMPO Y LA CIUDAD EN LA REFORMA AGRARIA: UN ANÁLISIS DEL TRABAJO Y DEL TERRITORIO}

\section{THE FIELD IN THE CITY AND AGRARIAN REFORM: AN ANALYSIS OF LABOR AND THE TERRITORY}

\author{
Eduardo Castro \\ Mestre em Geografia Humana pela Universidade de São Paulo e professor das \\ Faculdades Integradas Teresa Martin. castro-eduardo@usp.br
}

\section{Resumo}

O presente artigo tem como objetivo contribuir com o debate sobre as apropriações e usos dos espaços rural e urbano por famílias beneficiárias do Programa de Reforma Agrária do governo federal. Para tal, partimos de um estudo de caso realizado no Assentamento Ipanema, localizado no município de Iperó, estado de São Paulo. Para alcançar tal objetivo, elegemos a categoria trabalho, fundamental na análise marxista para explicar as características das sociedades humanas. Além disso, o trabalho está intimamente ligado com a vida, em sentido amplo, para as populações camponesas. A partir da análise das formas diversas de trabalho exercidas pelas famílias assentadas no campo e na cidade - avançamos no entendimento de como o espaço do lote e do assentamento é apropriado e construído pelos assentados, constituindo um território camponês em construção no interior do assentamento.

Palavras-chave: Campesinato, Reforma Agrária, Espaço, Território, Assentamento Rural.

\section{Resumen}

El presente artículo tiene como objetivo contribuir con el debate sobre las apropiaciones $\mathrm{y}$ usos de los espacios rural y urbano por familias beneficiarias del Programa de Reforma Agraria del gobierno federal. Para tal, partimos de un estudio de caso realizado en el Asentamiento Ipanema, localizado en el municipio de Iperó, estado de São Paulo. Para alcanzar tal objetivo, elegimos la categoría trabajo, fundamental en el análisis marxista para explicar las características de las sociedades humanas. Además, el trabajo está íntimamente relacionado con la vida, en un sentido amplio, para las poblaciones campesinas. A partir del análisis de las diversas formas de trabajo ejercidas por las familias asentadas - en el campo y en la ciudad - avanzamos en el entendimiento de

\footnotetext{
${ }^{1} \mathrm{O}$ presente artigo se baseia em nossa dissertação de mestrado, intitulada "O significado do trabalho na constituição da territorialidade dos assentados da Fazenda Ipanema, Iperó-SP", realizada sob orientação da Prof ${ }^{\mathrm{a}}$. Dra. Marta Inez Medeiros Marques e defendida em fevereiro de 2008 junto ao Programa de Pós Graduação em Geografia Humana da Universidade de São Paulo.
} 
cómo los asentados se apropian y construyen el lote y el asentamiento, lo que constituye un territorio campesino en el interior del asentamiento.

Palabras-clave: Campesinado, Reforma Agraria, Espacio, Territorio, Asentamiento Rural.

\begin{abstract}
The present article aims to contribute to the debate on the appropriations and uses of space for urban and rural families that take part of the Agrarian Reform Program of the federal government. To reach this purpose, the authors started their study from a case study conducted in Ipanema Settlement, located in the city of Iperó, state of Sao Paulo. To achieve this goal, they elected labor as a fundamental category in Marxist analysis to explain the features of human societies. Moreover, to peasant population labor is closely connected with life in broad sense. From the analysis of several concepts of labor carried out by families who settled - in the field and in the city - we move forward in the understanding how the lot and the settlement dimensions are appropriated and built by the settlers, being a peasant territory under construction inside the settlement.
\end{abstract}

Keywords: Peasantry, Agrarian Reform, Space, Territory, Rural Settlement. 


\section{Apresentação}

Este texto tem como objetivo contribuir para o debate referente às apropriações e usos dos espaços rural e urbano por famílias moradoras de assentamentos rurais, a partir das reflexões que fizemos em nossa pesquisa de mestrado (CASTRO, 2007), cuja área de estudo foi o Assentamento Ipanema, que se localiza no município de Iperó-SP.

O processo de territorialização de famílias assentadas em assentamentos rurais no Brasil tem sido estudado por muitos geógrafos, como Marques, Bombardi, Simonetti etc., fornecendo um importante arcabouço teórico para a compreensão desta realidade. Porém, as relações estabelecidas entre os assentados e as cidades próximas nem sempre têm sido analisadas mais detidamente.

O tema da territorialização de trabalhadores rurais assentados próximos de centros urbanos se insere na discussão sobre a dinâmica das relações entre o campo e a cidade no Brasil, que tem passado por intensas transformações nos últimos 50 anos. Estudar as maneiras através das quais as famílias assentadas garantem as condições materiais de sua existência na condição de moradores do meio rural e trabalhadores, tanto no campo como, em alguns casos, na cidade, é dar subsídios para a compreensão de uma realidade complexa e repleta de ambigüidades.

A análise de como as famílias se relacionam com essas formas espaciais (o campo e a cidade), espacializando-se de maneiras diferenciadas, pode lançar luz ao debate sobre o tema da territorialização e, dentro da Geografia Agrária, contribuir para a compreensão de quem são os sujeitos sociais que estão sendo assentados via luta dos movimentos sociais no Brasil e como eles vivem.

Para realizar tal reflexão, o nosso ponto de partida é a categoria trabalho. Isso se deve à centralidade que ela apresenta no processo de reprodução material e social de uma maneira geral, sendo uma categoria central na análise marxista, e que também se constitui em uma categoria fundante da ética e da moral camponesa (Woortmann, 1990). É a partir do estudo das formas de se relacionar com o espaço, tendo o trabalho como elemento principal dessa análise, que apresentaremos como que os espaços do campo e da cidade estão sendo apropriados pelas famílias assentadas. 


\section{Um breve histórico da luta pela conquista da terra em Ipanema}

O Assentamento Ipanema foi criado em dezembro de 1995, sendo dividido em 151 lotes que tem tamanhos que variam de 8 a 20 hectares, dependendo do tipo de solo e da quantidade de Áreas de Preservação Permanente que existe em cada um deles. As principais produções destas famílias são de olerícolas, hortaliças diversas, milho, mandioca, banana e goiaba.

Este assentamento faz parte do imóvel denominado Fazenda Ipanema, que ocupa 6.780 hectares. Destes, 5.179,93 hectares fazem parte da Floresta Nacional de Ipanema. Do restante, o Projeto Aramar ${ }^{2}$, do Ministério da Marinha, ocupa 879 hectares e o Ministério da Agricultura e Reforma Agrária possuía 721,07 hectares, referentes a um campo de aviação e suas imediações. O Projeto de Assentamento Ipanema foi constituído com uma área total de 1.712 hectares, dos quais, 1.210 hectares estão dentro da Floresta Nacional de Ipanema (cedida pelo IBAMA) e o restante (502 ha) foi cedido pelo Ministério da Agricultura e Reforma Agrária ao Instituto Nacional de Colonização e Reforma Agrária (INCRA). O Ministério da Agricultura continua com 219,07 ha, referentes ao campo de aviação, que não está em funcionamento ${ }^{3}$.

A articulação para a ocupação da Fazenda Ipanema iniciou-se no princípio de 1992, quando militantes do Movimento dos Trabalhadores Rurais Sem-Terra (MST), juntamente com algumas paróquias da Igreja Católica e sindicatos rurais começaram a organizar reuniões com famílias das periferias urbanas de treze municípios ${ }^{4}$, a maioria próximas da área a ser ocupada. Como normalmente ocorre nas ações de ocupação organizadas pelo MST e outros movimentos sociais de luta pela terra, até às vésperas da ocupação somente a liderança do movimento sabia onde esta ocorreria.

A área da fazenda faz parte da história da região, tendo sido alvo de interesses da coroa portuguesa desde o final do século XVI, devido à existência de minério de ferro no Morro de Araçoiaba, que fica na área. Mais recentemente, lá funcionava o Centro Nacional de Engenharia Agrícola (CENEA), que realizava pesquisas de melhoramento

\footnotetext{
${ }^{2}$ O projeto Aramar faz parte do Centro Tecnológico da Marinha em São Paulo (CTMSP). Esta divisão militar trabalha com pesquisa e desenvolvimento de sistemas nucleares e energéticos para propulsão naval, criado em 17/10/1986. Fonte: Marinha do Brasil, disponível em <www.mar.mil.br>, acesso em 25/10/2007.

${ }^{3}$ Informações obtidas através do Projeto técnico para implantação do Assentamento Ipanema, realizado pelo ITESP.

${ }^{4}$ Segundo relatos dos assentados, essas cidades foram as seguintes: Tambaú, Leme, Araras, Piracicaba, Santa Bárbara D’Oeste, Sorocaba, Porto Feliz, Indaiatuba, Hortolândia, Iperó, Campinas, Sumaré e Nova Odessa.
} 
genético de sementes, bem como um campo de aviação pertencente ao Ministério da Agricultura (MA), que servia para treinamento de pilotos agrícolas. Toda a extensão da Fazenda Ipanema pertencia à União, quando da ocupação desta.

Em 1990, o governo federal extinguiu o CENEA e deixou de utilizar o campo de aviação, abandonando a Fazenda Ipanema, bem como todas as máquinas e implementos agrícolas que lá existiam. Também todo o patrimônio histórico e cultural acumulado desde o século XVI foi "deixado às traças", .

O Governo Federal havia prometido que a Fazenda Ipanema seria destinada à reforma agrária, com a instalação de um assentamento rural. Passados dois anos do fim das atividades do CENEA e do MA, o MST decidiu realizar uma ocupação para pressionar a realização do assentamento prometido.

Na noite do dia 15 de maio de 1992, aproximadamente 700 famílias (em torno de 3.000 pessoas) ocuparam a área. Esta foi, na época, a maior ocupação já realizada no Estado de São Paulo pelo MST e uma das maiores do país até então. Esta ocupação teve grande repercussão na mídia devido a alguns motivos: além do número de pessoas, a área ocupada localiza-se muito próxima ao município e à cidade de Sorocaba. Com aproximadamente 600 mil habitantes, Sorocaba é um pólo regional, destacando-se pela importância de suas indústrias e comércio. Apesar da área ocupada localizar-se em Iperó, a mancha urbana de Sorocaba fica a aproximadamente $10 \mathrm{~km}$ da Fazenda, mais próxima, inclusive, do que a de Iperó.

Esta ocupação teve uma repercussão na mídia e no governo federal muito importantes. De um lado, esta ocorria muito próxima a uma grande cidade (Sorocaba), fato que não era tão comum à época. Por outro lado, estávamos às vésperas da Rio- $92^{6} \mathrm{e}$ como havia uma área de Mata Atlântica preservada próxima à área onde ocorreu a ocupação, esta foi a deixa para o presidente Fernando Collor, através do decreto número 530, de 20 de maio de 1992, transformar toda a área da Fazenda Ipanema em Floresta Nacional, passando esta a ficar sob administração do Instituto Brasileiro do Meio Ambiente e dos Recursos Naturais Renováveis (IBAMA).

\footnotetext{
${ }^{5}$ No século XIX, foi construída pelo governo imperial de D. João VI, a Real Fábrica de Ferro de Ipanema, responsável pela maior parte da produção siderúrgica brasileira daquela época, inclusive pela fabricação de armas utilizadas na Guerra do Paraguai. Esta atividade foi extinta no final do século XIX, dando lugar a uma exploração de fosfato para fabricação de adubo. Em meados do século XX, essa atividade mineradora também foi abandonada e o CENEA foi criado. (SALAZAR, 1998; SANTOS, 1999; SILVA, 1995)

${ }^{6}$ Conferência das Nações Unidas para o Meio Ambiente e Desenvolvimento, realizada na cidade do Rio de Janeiro em 1992.
} 
Aliado a esse fator, o fato de a maioria das famílias participantes da ocupação estarem morando no meio urbano antes desta ocorrer, aumentava a pressão da mídia e de outros setores conservadores da sociedade (inclusive do Estado) para que houvesse a reintegração de posse da área e não ocorresse a implementação de um assentamento rural na Fazenda Ipanema.

No entanto, os ocupantes da Fazenda Ipanema e o próprio MST não desistiram da luta. A ocupação contou com participação de militantes do MST de várias regiões do estado de São Paulo e de outros estados também, além do apoio da Igreja Católica, denotando a importância política e estratégica desta ocupação, além do alto nível de organização existente. Assentados nos relataram que receberam diversos apoios políticos de deputados estaduais, federais e senadores (Eduardo Suplicy, Aldo Rebelo, entre outros), o que foi fundamental para dar visibilidade e legitimidade à luta.

A pressão exercida contra as famílias ocupantes da Fazenda Ipanema pelos órgãos governamentais (IBAMA, Ministério Público, Polícia Militar etc.) foi bastante significativa. A Polícia Militar, mais de uma vez, ameaçou entrar na área do acampamento a fim de retirar os ocupantes, e sempre eram barrados na porteira da fazenda por mulheres e homens com facões e foices. Houve um episódio em que helicópteros da Polícia Militar jogaram panfletos sobre o acampamento incitando os acampados a desistirem da luta, dizendo que os militantes do MST eram bandidos e guerrilheiros. A história desse acampamento é como a de muitos no Brasil: composto pela luta e pela resistência diária frente às tentativas de desocupação da área, mesmo esta não sendo de propriedade de particulares.

Logo em seguida à ocupação, o governo entrou com pedido de reintegração de posse e foram iniciadas longas negociações dos militantes do MST que participavam da ocupação com órgãos e setores do governo federal como o IBAMA, INCRA e o Ministério da Agricultura que ainda controlava uma área dentro da Fazenda Ipanema, além da participação do ITESP (Instituto de Terras de São Paulo) a fim de se determinar quais áreas seriam passíveis de serem utilizadas para a instalação de um assentamento rural.

Foi realizado um estudo capitaneado pelo ITESP, com a participação do INCRA e do MST, no qual se verificou que existia uma área de 2.200 hectares passível de abrigar um assentamento, pois já eram agricultadas.

A partir disso começaram as discussões envolvendo o MST, IBAMA e INCRA, a fim de se conseguir que fosse cedida uma área para implantação de um assentamento 
rural. Diversas reuniões foram realizadas, assim como caminhadas e, até mesmo, ocupação do escritório do IBAMA em 1993, localizado na própria Fazenda Ipanema.

Cinco dias após a realização da ocupação no escritório do IBAMA, em uma audiência pública em Brasília, o IBAMA comprometeu-se a ceder para uso uma área de 1.210 hectares e os trabalhadores acampados passaram a produzir coletivamente na área ocupada. Este fato é relevante dentro da luta pela terra na Fazenda Ipanema, pois durante o período de acampamento as famílias começaram a produzir na área ocupada devido ao fato de estarem "dentro da terra", coisa que nem sempre ocorre nas ocupações no Brasil.

Em seguida, o ITESP, juntamente com as famílias acampadas, elaborou o projeto técnico para a implantação de um assentamento rural na Fazenda Ipanema. As negociações com o governo continuaram até que em 4 de dezembro de 1995 o INCRA promulgou a portaria número 342, criando o Projeto de Assentamento Ipanema, com 1.712 hectares (1.210 hectares do IBAMA e 502 hectares do Ministério da Agricultura e Reforma Agrária).

Das aproximadamente 700 famílias que participaram da ocupação, foram assentadas 151 famílias na área. Durante o período de quase quatro anos que durou a fase de acampamento na Fazenda Ipanema, muitas famílias foram desistindo da luta pela terra, devido às dificuldades existentes. Outro fato a ser colocado é o de que no ano de 1993, aproximadamente 100 famílias que estavam ocupando a Fazenda Ipanema foram para Tremembé-SP e ocuparam a Fazenda Petrobrás, onde hoje estão assentadas. Também na região de Martinópolis-SP, mais quarenta famílias oriundas da ocupação da Fazenda Ipanema foram assentadas.

A luta, no entanto, não termina com a conquista da terra e a criação do assentamento rural. Após a ida para o lote, começa a luta das famílias para estruturá-lo, para conseguir condições materiais que possam fazer com que o sonho pelo pedaço de chão seja efetivado definitivamente, para se apropriar e construir este espaço.

\section{Espaços construídos a partir do trabalho e da produção: em questão o processo de territorialização}

Para compreender como a construção do território se processa, não podemos abstrair os aspectos subjetivos de cada uma das famílias que foram beneficiadas pelo projeto do assentamento. Aspectos esses que estão relacionados a uma concepção do 
que é a vida no meio rural e de como deve se dar a construção desse lugar. Esses irão informar as práticas que irão se espacializar no assentamento.

Trata-se de construir toda a vida, projeto que está centralizado, a meu ver, na construção do novo lugar a partir da casa, da moradia familiar. Nessa construção a memória de outros lugares, vividos em outros tempos, marca os projetos individuais, familiares e grupais. Morar no assentamento se afigura para as famílias recém-chegadas, como um "novo tempo de viver" no qual se invertem as prioridades e, muitas vezes, até mesmo a relação espaço/tempo.

Pensar "assentamento" revela-se, portanto, como um exercício precioso, pois a chegada ao novo "LUGAR" (físico e social) de um universo considerável de famílias que passem a ocupar um espaço antes vazio socialmente (embora ocupado pelo latifúndio improdutivo) coloca a possibilidade de um exercício de pensar o "novo", ou seja, a chegada, o assentamento, a construção desse modo de vida. (D'AQUINO, 1996, p. 15)

O espaço do lote e do assentamento são construídos a partir da materialização das relações sociais travadas por esses assentados e suas famílias. Esse espaço não é uma coisa pronta, acabada, mero palco para que as relações sociais se desenvolvam, ele é fruto de uma construção. Construção essa que diz respeito, ao habitus dessas famílias, combinadas ao projeto que têm para si nesse novo lugar, aliadas às opções objetivas que se descortinam à sua frente.

O espaço é uma categoria social que expressa o tipo de espacialidade ou estrutura espacial apresentada pelo conjunto de relações sociais característico de uma determinada sociedade. Assim como as demais formas de objetivação das relações sociais, ele concorre para a constituição do habitus e incorporação do senso comum. Juntamente com o conceito de tempo, o espaço fornece um sistema de referência por meio do qual nós nos localizamos em relação ao mundo em que vivemos. A estrutura espaço-temporal atua como um princípio ordenador que situa e limita eventos e relações sociais, contribuindo de maneira significativa para a atividade de identificação e para o processo de reprodução social. Ao ser representado como uma relação natural entre as coisas ou pessoas, o espaço é naturalizado em seu contexto social de origem, implicando o que Soja (1993) chama de dialética sócio-espacial: "o fato de as relações sociais serem, simultânea e conflitantemente, formadoras do espaço e contingentes ao espaço." (op. cit.:155) A dialética sócio-espacial corresponde a uma face da dialética da objetivação e incorporação de que fala Bourdieu (1977), e está diretamente relacionada com o processo de reprodução social. (MARQUES, 2000, p. 27 - grifos do autor)

O espaço, portanto, é fruto de uma construção, de um processo social. Os espaços do lote e do assentamento são resultado da objetivação das relações sociais que as famílias desenvolvem ao longo de sua história de vida no assentamento. Da mesma 
forma, o espaço da cidade, o meio urbano com o qual as famílias se relacionam também possui um valor, uma importância e características que são relativas a cada família e a cada indivíduo que se relaciona com o mesmo. Há, evidentemente, uma hierarquia nos processos de construção do espaço urbano, que foge do alcance dos assentados. Mas isso não impede que haja uma apropriação dos espaços com os quais têm relação, também gerando um sentimento em relação a estes, mesmo que esse seja negativo.

A primeira questão que gostaríamos de abordar, em relação à apropriação e usos do espaço, diz respeito ao próprio espaço do lote. A construção desse espaço está relacionada a aspectos subjetivos, que têm relação com a chegada a "um espaço vazio" e à sua conseqüente apropriação, construção e contínua reapropriação. Há diferenças na forma de encarar esse espaço entre aqueles assentados que só trabalham no mesmo e aqueles que também trabalham na cidade.

Em primeiro lugar, procuramos ver o lote como o local de morada, e nesse sentido, como o espaço em que a família vai se relacionar e, a partir dele, expandir suas relações.

\footnotetext{
Nesse contexto a casa é o centro, o espaço por excelência de construção da vida familiar. Não por acaso, em geral ela está situada no meio do lote, feita de alvenaria e mobiliada com novos armários, geladeiras e fogões e uma ou outra peça do velho mobiliário herdado, que resistiu a tantas migrações e até mesmo correrias da polícia ou estouros de boiadas propositadamente jogadas sobre os acampamentos. Ela guarda, junto com velhas lembranças, os sonhos de liberdade. (D'AQUINO, 1996, p. 25)
}

A autora citada acima descreve como na área que realizou seu estudo (Fazenda Reunidas em Promissão-SP) a casa é o primeiro espaço a ser construído e apropriado pela família ao ser assentada. Isso independe se a mesma é de alvenaria ou de madeira, por exemplo. Transcorridos mais de onze anos da constituição do Assentamento Ipanema são várias as casas de assentados (se não for a maioria) que são de madeira, muitos as chamando de "barraco". Somente agora, com a liberação de um crédito de R\$ 8.000,00 a fundo perdido da Caixa Econômica Federal é que muitos assentados estão tendo a oportunidade de construir casas de alvenaria ou, aqueles que já as possuíam, de finalizá-la.

A construção da casa vai depender das condições financeiras de cada família no momento em que vão para os lotes definitivos e de como essa situação vai se alterar ao 
longo dos anos. O crédito moradia liberado pelo INCRA quando da instalação do assentamento foi de $\mathrm{R} \$ 3.000,00$. Muitas famílias preferiram começar a organização da produção com esse valor, pois desta depende a sobrevivência imediata da família. Mas o fato de não possuírem uma casa de alvenaria não significa que a apropriação da casa seja "incompleta". Observamos na casa de vários assentados flores enfeitando a entrada e dentro da casa, tudo muito limpo e arrumado, apesar dessas serem de madeira.

A apropriação e construção do espaço do lote se dá, portanto, a partir da casa e da produção nele estabelecida. Percebemos que aqueles que não trabalham somente no lote parecem ter uma apropriação diferente em relação a este, a partir do que eles próprios relatam. Ao caminhar nesses lotes com os assentados, estes sempre vão buscar justificativas para tal cultura estar "meio largada", ou em determinado local o mato estar maior do que eles gostariam. Percebe-se uma certa vergonha em relação a estes fatos.

Já os assentados que estão trabalhando somente na produção agrícola no lote têm, em geral, muito orgulho de mostrar coisas que, para nós, muitas vezes passam desapercebidas. Por exemplo, um assentado, o Sr. Paulo Bernardo, mostrou-nos muito orgulhoso que possuía alguns pés de cana caiana. Outro assentado, o Sr. Ligeirinho, aproveitando um "rego d'água" que passa em seu lote, construiu uma espécie de piscina, onde, segundo ele, se refrescará no verão.

Isso mostra, que a apropriação e a espacialização no lote têm uma dimensão que vai além do trabalho agrícola em si. O domínio do lote e a construção de “equipamentos" que, não são destinados à produção propriamente dita, é muito comum entre os assentados, deixando aquele espaço "do seu jeitinho".

Um assentado, o Sr. Maluf, que voltou a trabalhar somente no lote há aproximadamente dois anos, vem aos poucos mexendo no mesmo e procurando também deixá-lo mais aprazível. Reclamou que precisa reformar o pasto e que ainda não teve tempo de fazê-lo, mas já se percebe uma relação diferente da de outros assentados, como o Sr. Jânio, por exemplo, que trabalha de segunda a sábado na cidade. Ele mostrou descontentamento e até um certo desgosto com o estado do lote, dizendo que as coisas estavam meio largadas, pois não conseguia ter tempo para ajeitá-las.

Dessa forma, são várias as maneiras de se apropriar de construir o espaço de cada lote. Essas maneiras estão, em boa medida, relacionadas aos trabalhos que ali são executados e ao tempo que conseguem permanecer ali sem estar trabalhando, tendo um tempo livre. 
Durante os anos de acampamento, relações de amizade, solidariedade, vizinhança, e mesmo de parentesco são travadas entre os acampados. Com o estabelecimento do assentamento essas relações têm a possibilidade de ter continuidade e de se fortalecerem.

Após 11 anos da constituição do assentamento rural, percebemos que o sentimento de identidade, de pertencimento ao lugar é muito forte. Todos se conhecem, apesar do grande tamanho do assentamento. Sempre encontramos assentados fazendo visitas a outros, sejam mulheres ou homens.

Os motivos das visitas são bem variados, desde tomar um café com a comadre, até pedir sugestões sobre a forma como lidar com uma plantação ou uma criação. Tivemos a oportunidade de presenciar um assentado matando um boi e outro assentado ajudando-o, inclusive a cortar a carne. A pessoa que forneceu a ajuda não consumiu a carne do boi, mas percebemos que estava se divertindo com a atividade, conversando com as pessoas, tomando uma cachacinha, enfim, vivenciando uma sociabilidade típica camponesa.

Redes sociais são tramadas dentro do assentamento. Já são vários os casos de filhos de assentados que casaram entre si, inaugurando uma relação de parentesco naquele espaço que outrora não existia e que pode ser característica da próxima geração residente no assentamento. Por exemplo, o filho mais novo do Sr. Ligeirinho casou-se recentemente com a filha de um assentado e estão morando no lote deste último; a filha do Sr. Sergião, outro assentado, já é casada há alguns anos com outro assentado, sendo que eles compraram o lote ao lado do lote do Sr. Sergião; o irmão do Sr. Edson também casou-se logo quando os lotes definitivos foram conquistados; o Sr. Maluf, como já dissemos, casou-se ainda durante a ocupação; enfim, percebemos que esses laços vão sendo criados e fortalecidos.

Redes de solidariedade e de ajuda mútua também vão sendo estabelecidas. Mulheres se reúnem para fazer o pão que vai ser consumido e vendido por elas, como é o caso das assentadas Dona Vera, Dona Elza e Dona Dulce. Famílias se unem para realizar mutirões para auxiliar um assentado num momento de necessidade.

Sr. Alaor: É um momento marcante [do mutirão]. Às vezes você é vizinho do cara e fica um mês sem ver ele, então ali nego rasga seda, conta piada, conta as novidades e as experiências do serviço dele... então a gente passa a saber. É uma coisa boa, muito boa, vixe, coisa ótima! (assentado, entrevista concedida em maio de 2006) 
Em junho de 2007, a casa de um assentado, o Sr. Sergião, pegou fogo, sendo destruída completamente. Em uma semana, os assentados organizaram uma festa e conseguiram arrecadar mais de $\mathrm{R} \$ 3.000,00$, que serviu para o Sergião iniciar a reconstrução de sua moradia.

Além do mutirão, é muito comum os assentados trocarem produtos entre si. Oferecer produtos aos vizinhos é uma outra forma de solidariedade típica, que vai propiciar a muitas famílias o consumo de produtos alimentícios sem a necessidade de dispender recursos financeiros para adquiri-los.

Sr. Valdemar: Aqui os amigos passam, a gente oferece alguma coisa a eles, depois a gente vai lá, se tem alguma coisa a gente traz, é assim, divide. (assentado, entrevista concedida em julho de 2007)

Edson: Então, apesar de eu não ter muita variedade no meu lote, hoje se eu for ver eu tenho o quê? A goiaba parou de produzir, normalmente a gente tem umas bananas, tem um capãozinho ali que é básico pro consumo [...] tem um pezinho de chuchu, umas galinhas, um ovinho, um leitinho... mas o que eu uso muito com o pessoal aqui, eu sou meio cara de pau, a gente faz muita troca, né. Então, a minha feira eu faço aqui com os vizinhos. O que você tem lá sobrando? Quem tem um pé de chuchu, ele não come tudo, sobra, né. Então eu passo lá, tal coisa você pega lá na minha casa, e tem várias famílias, não é a maioria talvez, mas várias famílias que faz isso. $O$ que você tem? Tenho um limão ali, mas o limão é muito pro meu consumo, mas é pouco pra venda, não vendo ele. O cara já vem e leva uma sacolada de limão, então a gente faz essas trocas aí. E aí, que se eu for fazer esse balanço no final do mês, né, só essa base de legumes que a gente troca aqui, eu consumo, a gente consome uma variedade aí, acho, de uns dez produtos assim no mês entre, vamos dizer: mandioca, jiló, berinjela, chuchu, pimenta, pimentão, quiabo, é o que é mais produzido por aqui, né. (assentado, entrevista concedida em maio de 2006)

Essa solidariedade entre os vizinhos, como nos relatou o Sr. Edson, é muito comum e também é um elemento muito forte no estabelecimento dos laços e das relações sociais entre os assentados. Todas as vezes que fomos ao assentamento, além de tomar café, almoçar (às vezes mais de uma vez no mesmo dia), pernoitar nas casas dos assentados, eles sempre nos ofereciam coisas nas nossas visitas: goiabas, verduras, legumes, inclusive uma vez saí com um cacho de bananas no porta-malas do carro. Sempre nos ofereciam os frutos do seu trabalho com o maior prazer e orgulho de nos mostrar a qualidade do que tinham produzido.

Tivemos também a oportunidade de freqüentar alguns bares que ficam no assentamento durante os trabalhos de campo que realizamos e percebemos também que 
estes são lugares de socialização, principalmente dos homens, onde as pessoas se encontram para saber as novidades, marcar reuniões etc.

Sempre há a ocorrência de festas no assentamento. Além das tradicionais festas juninas e da festa de aniversário da ocupação, sempre há festas de aniversário que reúnem várias famílias. Nas festas coletivas, as mulheres, em geral, tomam a iniciativa de vender rifas, coletar doações de animais e outros produtos alimentícios para que a fartura da mesma seja garantida. Na festa dos 14 anos da ocupação, em 1996, havia duplas caipiras cantando, um locutor de rodeio amigo dos assentados anunciando as atrações da festa, além de muita comida, bebida e mesa com jogo de truco (da qual eu e meu parceiro, o Sr. Moacir, saímos invictos na noite!).

O Sr. Sergião nos relatou que quase todo final de semana organiza um forró entre os vizinhos, que vai até alta madrugada. Relembra que durante a ocupação, não tinha um dia praticamente em que não havia um forró para os assentados se distraírem um pouco das tensões do dia-a-dia, sempre com um sanfoneiro que era acampado e hoje é assentado em Ipanema.

Enfim, percebemos que há uma efetiva apropriação desse espaço, gerando um processo de territorialização do conjunto dessas famílias em relação ao assentamento. A casa, o lote, o assentamento não são apenas espaços onde se dorme, apenas uma moradia para famílias que vivem da realização de atividades diversas, inclusive não agrícolas. Nesse sentido, a concepção de território aqui adotada passa pela noção de apropriação de um espaço por um conjunto de pessoas, nesse caso, das famílias do assentamento.

Entende-se território como o espaço de reprodução da existência de uma sociedade ou grupo social, formado com base em um contrato social firmado entre os seus membros e definido a partir de relações de apropriação e domínio. O contrato social corresponde a um conjunto de princípios, explícitos ou não, que regem e orientam as relações sociais numa dada forma social, inclusive as relações que definem as formas de apropriação da terra e o regime de propriedade. Aqueles que compartilham um mesmo território devem estar submetidos a uma mesma "lei". (MARQUES, 2000, p. 30 - grifos do autor)

Então, há um relativo controle desse espaço, o que faz com que essas pessoas se sintam pertencentes ao mesmo, tenham uma sensação de segurança de permanecer ali, de não serem expropriadas novamente, o que garante uma apropriação profunda desse espaço, gerando o processo de territorialização. 
O assentamento é a expressão concreta da territorialização do movimento. Não é somente o lugar da produção, mas também o lugar da realização da vida. [...] E a vida, para esses camponeses, como se verifica em seus relatos, não é somente ter comida, ter casa, mas uma vida plena, uma vida cheia de significados, na qual aquilo que eles crêem tem possibilidade de continuar sendo respeitado e existindo: sua cultura, sua autonomia, sua visão de mundo, sua capacidade de crescer a partir de suas próprias potencialidades, enfim seu universo simbólico. (SIMONETTI, 1999, pp. 70-71)

O processo de territorialização dessas famílias envolve, portanto, a dimensão cultural, simbólica. É a materialização no espaço e nas relações sociais que são desenvolvidas a partir desse espaço, de uma trajetória de luta e de um futuro de sonhos. É, nesse espaço, que a maioria das famílias assentadas realizam seus projetos de vida, projetos esses que têm como dimensão fundamental suas famílias.

E, em relação ao espaço urbano, quais dimensões podem ser apreendidas das diferentes modalidades de inserção, de relação e de apropriação que as famílias da Fazenda Ipanema possuem com ele? Quais são as diferenças entre aqueles assentados que trabalham na cidade, aqueles que comercializam sua produção nela e os que apenas a utilizam para as compras necessárias e para o uso dos equipamentos públicos como hospitais, escolas, correio etc., tendo em vista que essas relações não são obrigatoriamente excludentes?

Algumas lideranças dos assentados têm relações mais estreitas com o meio urbano, pelo fato de possuírem uma atividade política, sobretudo em negociações com o ITESP sobre assistência técnica e com o INCRA sobre liberação de recursos etc. Evidentemente, as redes de relações sociais que são desenvolvidas variam de acordo com a forma como os assentados se inserem na cidade. E o trabalho é um elemento importantíssimo para compreendermos como essas relações se constituem e se desenvolvem.

As relações que a maioria dos assentados, chefes de família (os que só trabalham no lote), possuem com a cidade são decorrentes de sua função de fornecedora de serviços. Dessa forma, o comércio (tanto de insumos agrícolas, quanto de bens de consumo para a casa), os serviços médico-hospitalares, agências bancárias e o escritório do ITESP em Sorocaba são os principais recursos a que essas famílias recorrem.

Pelo fato de a cidade de Sorocaba ser muito maior que a de Iperó, é em Sorocaba que a maior parte das necessidades dos assentados é suprida. Com exceção da compra 
de insumos agrícolas que são adquiridos, em sua maioria, no município de Capela do Alto, que possui várias lojas especializadas nesse ramo.

Para se locomover até a cidade de Sorocaba, há um ônibus que passa dentro do assentamento e que vai e volta para essa cidade uma vez pela manhã e uma vez à tarde. Além isso, existe uma linha regular que liga as cidades de Sorocaba e Iperó, que possui mais horários. No entanto, este ônibus não entra no assentamento e os assentados têm que se locomover até a estrada que liga essas cidades para apanhá-lo. Dependendo do lugar em que o assentado mora, tem que ser feita uma caminhada que varia de 5 a 30 minutos. São poucos os assentados que possuem automóveis, o que facilita o deslocamento para esses.

Muitos são os relatos de assentados que dizem que vão à cidade apenas para 0 necessário, inclusive com depoimentos de que "é só chegar na cidade e a cabeça já começa a doer" (Sr. Otacílio) ou de que querem sair de lá o mais rápido possível. Percebe-se que a relação com a cidade não é prazerosa, muito pelo contrário. Acreditamos que a cidade representa, em certa medida, algo que lhes é externo, ao qual não pertencem e que suscita uma relação de topofobia ${ }^{7}$ com esse espaço. Acreditamos que o que traumatiza sejam sobretudo as frustrações, a não integração, a insegurança pessoal e familiar, o fato de se estar à mercê da vontade de outros e o sentimento de injustiça e de humilhação que essa situação gera. Todos estes aspectos estão relacionados a uma inserção precária no mundo do trabalho. Além disso, também é preciso considerar as marcas relacionadas ao sentimento, vivenciado em muitas situações, de que se é um estranho perdido no meio da cidade grande.

Para estes trabalhadores, o trauma vivenciado na cidade (moradia em lugares insalubres, violência, dificuldades de toda ordem no trabalho, separação da família, desemprego, transporte, fome, trabalho nas

\footnotetext{
${ }^{7}$ A aceitação passiva da realidade geográfica pode ser rompida por experiências capazes de provocar sensações intensas - e mesmo fracas, ou até mesmo tão ordinárias que não despertam a consciência geográfica e sim uma consciência voltada à qualidade daquilo que é oferecido pelos ambientes experenciados. Se estas experiências são positivas e agradáveis, são experiências de Topofilia. Se, ao contrário, são experiencias repulsivas e desagradáveis, são experiências de Topofobia. Os dois termos, cunhados por Bachelard em 1969, foram ampliados por Tuan (1974) para abarcar não só as experiências relacionadas com os espaços, mas também as experiências com lugares e paisagens, conforme nos explica Relph (1979). Topofilia, relaciona-se com sentimentos direcionados ao lar, para aquilo que é confortável, sem confusões ou tensões. Inclui também as experiências de êxtase contemplativo dos lugares, assim como os componentes persuasivos das paisagens atraentes. Tudo aquilo que nos leva a relaxar e a nos sentir estimulados, dando-nos prazer, relaciona-se com a Topofilia. De acordo com o ambiente ou as circunstâncias, as experiências de lugares e paisagens podem ser Topofóbicas. Isso acontece quando envolve as sensações de medo e receio, ou quando o observador se sente rejeitado pelo ambiente. São experiências que, sendo de algum modo desagradáveis, induzem à sensação de ansiedade ou depressão. (LASSALVIA, 2004, p. 57-58 - grifo nosso)
} 
fábricas, controle do trabalho e do tempo etc.) explica a recusa e a resistência a esta proletarização, fazendo emergir o desejo de mudança, através da luta pela terra e da reafirmação de um projeto de vida que tem a terra como fundamento de um modo de ser, de pensar e de estar no mundo. (SIMONETTI, 1999, p.118)

Mesmo entre os assentados que comercializam sua produção na cidade, seja em feiras ou de porta em porta, há a percepção de que essa tarefa é árdua. O Sr. Luis Carlos, por exemplo, durante muitos anos foi feirante em Sorocaba. Apesar de essa atividade ter um grande peso na renda da unidade familiar, havia uma sensação expressa na sua descrição desta atividade sempre relacionada a um cansaço acompanhada de uma insatisfação, uma vontade de não mais realizá-la. Tanto é que, agora, este assentado está procurando evitar ter que realizar esse comércio, devido ao surgimento da possibilidade de comercializar sua produção pelo $\mathrm{PAA}^{8}$ e pela recente autorização que o IBAMA concedeu para que os assentados comercializassem a sua produção em sua sede na Fazenda Ipanema. Segundo o Sr. Luis Carlos, é preferível vender no IBAMA por não precisar madrugar (para fazer feira, acordava às 4 da manhã aos finais de semana), pelo deslocamento ser bem menor, e pelo fato de ser muito mais tranqüilo ficar por ali, ao lado do assentamento, que enfrentar a confusão da ida e volta da cidade, a gritaria, agitação e tumulto própria feira.

Já os assentados que trabalham na cidade, além do trabalho no lote, têm diferentes percepções daquele espaço. Em entrevista com um assentado, o sr. Maluf, este nos relatou que quando trabalhava na cidade, "não se sentia mal não". Sua vontade era a de trabalhar somente na terra, coisa que está conseguindo fazer há dois anos. Hoje, este assentado possui um Fusca e tem condições de levar sua mercadoria até os compradores e, como sua esposa tem problemas de saúde, chega ao consultório médico com mais rapidez e comodidade.

O Sr. Jânio é um dos assentados que continua trabalhando na cidade. Sua fala é bastante ambígua em referência ao sentimento que possui em relação à cidade.

Eduardo: Qual a melhor coisa de morar aqui no assentamento? Jânio:Tem mais sossego, né? Pelo menos os filhos não cai nas bandidagem da cidade, na cidade tem bandidagem, né? O cara que não estuda vai pra bandidagem, agora o cara que estuda ele não vai. [...]

\footnotetext{
${ }^{8}$ Programa de Aquisição de Alimentos da Agricultura Familiar. Esse programa do governo federal oferece a possibilidade de cada família assentada pode vender R $\$ 3.500,00$ por ano em mercadorias agrícolas de qualquer tipo. Esse programa começou a funcionar em 2006 e vêm beneficiando um número cada vez maior de famílias em Ipanema.
} 
Agora aqui não, pelo menos os filhos não tá vendo nada de malvado da cidade, malvadeza...

Eduardo: E a pior coisa de morar aqui?

Jânio: Não, aqui é tudo bom. A pior coisa às veiz a gente quer comprar algum um objeto pra gente, pra família da gente e naquele tempo não tem como comprar. Uma roupa, um carçado, ou uma bicicleta prum filho que quer e as vez não tem como comprar. As veiz nem que a gente tenha uma novilha aí, a gente fala, vamo vender essa novilha pra comprar uma bicicleta. Vende a novilha e não consegue comprar a bicicleta porque tem outras coisa pra comprar dentro de casa. Acontece isso aí com a gente, aconteceu isso aí comigo já! E tem as conta né? Ah, vamo vender uma novilha dessa pra mim fazer alguma coisinha, né? Aí as conta, na hora aparece as conta e aí já desintera as conta. Na cidade é duro, pro cara morar na cidade é duro. Mas se ele tiver o emprego dele, a casinha dele não é difícil não. $\mathrm{E}$ tem estudo também né? Sem estudo não veve na cidade não. Veve na bandidagem muito, né? (assentado, entrevista concedida em julho de 2007)

Há vários aspectos interessantes e reveladores na fala transcrita acima. De um lado, as qualidades de morar no assentamento são concebidas em oposição aos problemas da cidade. $\mathrm{O}$ assentamento é tranqüilo, não há "bandidagem". A visão da cidade é, como dissemos, ambígua. Há a percepção de que sem estudo, não há possibilidades de se viver com dignidade, mas há o atrativo do consumo, que, na sua visão, morar e trabalhar na cidade pode propiciar com mais facilidade. Há uma idealização de que, ao se ter um elevado grau de instrução, o morador da cidade teria uma facilidade muito maior em consumir aquilo que quisesse, na hora que quisesse. Ora, sabemos que as coisas não são dessa maneira, mesmo porque o que os indivíduos desejam, almejam, sonham consumir são relativos à posição social que ocupam em determinado momento. Assim, se para esse assentado o "sonho de consumo" em um determinado momento é uma bicicleta para o filho, para um trabalhador da classe média urbana pode ser um televisor de plasma. Ambos os desejos são difíceis de se obter a qualquer momento.

Outro aspecto diz respeito à inserção desse e de outros assentados como consumidores na economia capitalista. Existe uma dificuldade em garantir necessidades materiais que são básicas. Essa bicicleta para o filho, além de propiciar lazer, pode ser um importante meio de transporte dentro do assentamento. Há uma desigualdade entre os preços dos produtos agrícolas e o dos produtos de origem industrial que os assentados necessitam consumir (roupas, calçados, materiais escolares etc.). Muitos autores abordam a questão da transferência de renda da agricultura para outros setores da economia, da expropriação da renda camponesa da terra pelo capital comercial e 
industrial. Além disso, o significado de vender uma novilha para comprar algum produto para consumo corrente, ou mesmo pagar contas do dia-a-dia da família é muito revelador, pois em geral o gado é uma reserva de valor, cuja venda se faz necessária em momentos de apuro ou para se fazer um investimento. Esse fato pode demonstrar o grau de dificuldade financeira pela qual essa família vem passando.

Por outro lado, em outro trecho da mesma entrevista, fica claro que o Sr. Jânio não sente que tem um lugar para ele na cidade.

Sr. Jânio: Cidade é vocação... pro cara morar na cidade, ele tem que trabalhar sábado e domingo direto. Ele não tem feriado, na roça não, na roça a pessoa não tem nada, mas também não se preocupa com nada. O maior problema nosso é que nós morava no interior e nós veio tudo sem estudo pra cidade, isso é o que mais prejudicou a gente. A gente já com 20 anos já veio pra cidade e tinha que trabalhar, analfabeto, sabe cara analfabeto? Eu tenho irmão até hoje que não sabe escrever o nome. (assentado, entrevista fornecida em julho de 2007)

Para este assentado, só é possível viver na cidade tendo estudado. Neste trecho acima transcrito fica claro que o mesmo não teve possibilidade de estudar. Estas questões estão presentes nas situações e nas formas que os assentados lidam com a objetividade que se põe à sua frente.

A maneira como os assentados "se sentem" em relação à cidade, demonstrando o que $\operatorname{Tuan}^{9}$ (1980 apud LASSALVIA, 2004) chama de topofobia em relação a este espaço é uma das facetas do processo de espacialização no meio urbano. Evidentemente, essa é apenas uma das facetas que esses assentados e suas famílias podem desenvolver em relação à cidade. $\mathrm{O}$ aspecto político, no que diz respeito ao direito de utilizar os equipamentos públicos, e sua efetiva utilização, é algo que não podemos deixar de considerar.

O acesso à educação é o primeiro elemento que julgamos ser fundamental a esse respeito. Os filhos dos assentados, dependendo de onde moram no assentamento vão às escolas do bairro de George Oeterer ou de Bacaetava, ambos do município de Iperó. Essas escolas têm Ensino Fundamental e o Ensino Médio e há um ônibus da prefeitura de Iperó que leva e traz os alunos para a escola todos os dias. Em relação a essa questão, portanto, a avaliação geral dos assentados é de que eles são bem atendidos.

Outros serviços essenciais são o de saúde. Em relação a estes, o quadro não difere muito do que ocorre nas periferias das cidades. Há dois postos de saúde próximos

\footnotetext{
${ }^{9}$ TUAN, Yi-Fu. Topofilia. São Paulo: Difel, 1980.
} 
ao assentamento, mas os assentados se queixaram conosco que há muita demora em se marcar consultas e que exames e especialidades médicas em geral não são atendidas nestes. Por isso, com freqüência, há a necessidade de se deslocarem até o centro de Iperó ou um bairro mais distante de Sorocaba.

Em relação aos serviços bancários, também há a necessidade de se deslocarem ao centro de Iperó, pois a agência bancária do Banco do Brasil mais próxima, onde fazem os financiamentos do PRONAF, por exemplo, localiza-se lá. Há uma reclamação a esse respeito, pois a agência é pequena e, segundo eles, a gerência, muitas vezes, não os trata bem.

Em relação à religião, há missa todos os domingos em uma capela da Igreja Católica existente no assentamento. No entanto, não são todos os assentados que têm fácil acesso ao local em que essa se encontra, devido ao tamanho do assentamento. Além da capela, há várias igrejas pentecostais e neopentecostais no assentamento (em torno de seis, não foi possível apurar o número exato), sendo o acesso a essas mais fácil, pois estão mais espalhadas pela área.

Em relação aos serviços públicos da prefeitura, ITESP e INCRA, em geral são as lideranças dos assentados que fazem a interlocução com esses órgãos. Presenciamos algumas oportunidades em que técnicos do INCRA foram ao assentamento realizar reuniões gerais com as famílias. A pauta dessas reuniões costuma ser sobre assuntos específicos, como a liberação dos recursos da Caixa Econômica Federal para a reestruturação das moradias do assentamento, por exemplo. As discussões de caráter mais geral, como sobre as políticas públicas, são realizadas pelas lideranças.

Percebemos, então, que os assentados se relacionam com a cidade de diversas formas. A proximidade é um fator importante no que diz respeito ao acesso aos serviços públicos. Como nos relatou o Sr. Otacílio, quando era criança precisava fazer uma caminhada de praticamente duas horas para chegar à escola, hoje ela está "logo ali". Apesar disso, como as relações tramadas com o meio urbano, no passado, não trazem boas recordações, a maioria relata que vai à cidade somente quando há necessidade. Essa não é utilizada para fazer passeios, para desenvolver atividades culturais etc. A visita a algum parente é o motivo que leva os assentados a ficarem um tempo mais longo na cidade.

Mas a cidade é mais do que uma mera prestadora de serviços públicos. Também se constitui em uma importante alternativa de geração de renda, em face das 
dificuldades que, muitas vezes, os assentados encontram para se sustentarem economicamente apenas com o trabalho na própria terra.

Mais do que isso, a cidade é um símbolo de um modo de vida pelo qual a maioria passou e renunciou, preferindo viver e trabalhar no campo, na terra. Renunciar à vida na cidade e aos trabalhos urbanos como primeira opção de vida não significa, no entanto, renunciar a tudo que esta significa e pode fornecer, como é o caso dos serviços públicos já mencionados.

O que queremos ressaltar é que, em face dessas relações que são tramadas, evidentemente há um processo de espacialização mais profundo em relação ao espaço do assentamento, que gera, como já dissemos, um processo de territorialização, a constituição de um território camponês. Território esse que não está isolado, integra-se de maneiras diversas ao urbano que o cerca e também aos outros territórios camponeses em construção, descontínuos a este. 


\section{Considerações finais}

Consideramos extremamente importante a discussão sobre como ocorrem os processos de ocupação do espaço nos dias atuais. Seja no campo ou na cidade, ter a posse, apossar-se, poder se enraizar é uma possibilidade cada vez mais rara. Em uma sociedade marcada pela velocidade e pelos desenraizamentos sucessivos, fixar-se, sentir a terra firme sob os pés pode ser o maior dos portos seguros.

No caso que ora estudamos, essa terra, depois de conquistada, é reapropriada e reconquistada sempre que um trabalhador e uma trabalhadora regam uma horta, tomam o leite de sua vaca, adubam seu cultivo, descansam à sombra de algum abacateiro, mangueira, jaboticabeira... e tantas outras coisas que mereceriam vários tratados e prosas sobre o assunto.

A construção desse novo espaço, o Assentamento Ipanema, é fruto das lutas para sua conquista e de todas as relações que vão se formando e se transformando dia a dia. Relações e laços de parentesco, de amizade, religiosos, de compadrio etc.

A cidade é outro espaço, complementar ao do assentamento e em íntima relação com esse. Complementar, porém distinto. As apropriações do espaço que são realizadas pelos assentados na cidade também vão ser mediadas pelas relações que são estabelecidas, pelos vínculos que vão sendo criados ao longo do tempo.

Enfim, compreender como ocorrem esses processos de espacialização e territorialização é extremamente importante para entendermos parte da dinâmica espacial da sociedade atual. Conhecimento este que é fundamental para pensarmos e repensarmos todas as políticas públicas que envolvem as famílias assentadas no Brasil hoje, bem como as de amanhã.

\section{Referências}

CASTRO, Eduardo. O significado do trabalho na constituição da territorialidade dos assentados da Fazenda Ipanema, Iperó,SP. São Paulo, 2007. 151 f. Dissertação (Mestrado em Geografia Humana) - Faculdade de Filosofia, Letras e Ciências Humanas, Universidade de São Paulo.

D’AQUINO, Teresinha. A Casa, os sítios e as agrovilas: uma poética do tempo e do espaço no assentamento das Terras de Promissão-SP. In: ENCONTRO ANUAL DA ANPOCS, 20., 1996, Caxambu. Anais do XX Encontro Nacional da ANPOCS. 
Caxambu: Associação Nacional de Pós-Graduação e Pesquisa em Ciências Sociais, 1996.

LASSALVIA, Melissa Marina. Imagens de um Mundo Vivido: um estudo das paisagens do centro da metrópole paulistana com base na percepção da população usuária. São Paulo, 2004. Monografia (Trabalho de conclusão de curso em Geografia) - Faculdade de Filosofia, Letras e Ciências Humanas, Universidade de São Paulo.

MARQUES, Marta Inez Medeiros. De sem-terra a "posseiro", a luta pela terra e a construção do território camponês no espaço da reforma agrária: o caso dos assentados nas fazendas Retiro e Velha - GO. São Paulo, 2000. 240 f. Tese (Doutorado em Geografia) - Faculdade de Filosofia, Letras e Ciências Humanas, Universidade de São Paulo.

SALAZAR, José Monteiro. Araçoiaba \& Ipanema: a história daquela maravilhosa região, desde as forjas de Afonso Sardinha até a Real Fábrica de Ferro. Sorocaba: Digipel, 1998.

SANTOS, Elina O. A Industrialização de Sorocaba: Bases Geográficas. São Paulo: Humanitas FFLCH/USP, 1999.

SILVA, Paulo Celso da. De novelo de linha a Manchester paulista: Fábrica têxtil e cotidiano no início do século XX em Sorocaba. São Paulo, 1995. Dissertação (Mestrado em Geografia) - Faculdade de Filosofia, Letras e Ciências Humanas, Universidade de São Paulo.

SIMONETTI, Mirian Claudia Lourenção. A longa caminhada: (re) construção do território camponês em Promissão. São Paulo, 1999. 200 f. Tese (Doutorado em Geografia) - Faculdade de Filosofia, Letras e Ciências Humanas, Universidade de São Paulo.

WOORTMANN, Klaas. "Com parente não se neguceia": o campesinato como ordem moral. In: Anuário Antropológico/87. Brasília/Rio de Janeiro: Edunb/Tempo Brasileiro, 1990. 